\title{
Randomized clinical trial evaluating the frequency of membrane sweeping with an unfavorable cervix at 39 weeks
}

This article was published in the following Dove Press journal:

International Journal of Women's Health

18 August 2011

Number of times this article has been viewed

\author{
Kathleen Putnam' \\ Everett F Magann ${ }^{2}$ \\ Dorota A Doherty 3 \\ Aaron T Poole' \\ Marcia I Magann² \\ William B Warner' \\ Suneet $P$ Chauhan ${ }^{4}$ \\ 'Department of Obstetrics and \\ Gynecology, Naval Medical \\ Center - Portsmouth, Portsmouth, \\ Virginia, USA; ${ }^{2}$ University of Arkansas \\ for Medical Sciences, Little Rock, \\ Arkansas, USA; ${ }^{3}$ School of Women's \\ and Infants' Health, University of \\ Western Australia, Perth, Australia; \\ ${ }^{4}$ Aurora Healthcare, West Allis, \\ Wisconsin, USA
}

Background: Despite the widely accepted use of membrane sweeping to prevent postmaturity pregnancies, the optimal frequency for this procedure has not been established.

Aim: To determine if the frequency of membrane sweeping in women with an unfavorable cervix at term results in fewer labor inductions.

Methods: This was a randomized trial of women with an unfavorable cervix (Bishop's score of $\leq 4$ ) at 39 weeks randomized into three groups: control, once-weekly membrane sweeping, and twice-weekly membrane sweeping.

Results: Between January 2005 and June 2008, 350 women were randomized into the study (groups: control [ $\mathrm{n}=116]$, once weekly [ $\mathrm{n}=117]$, and twice weekly [ $\mathrm{n}=117]$ ). Randomization of Bishop's score was different between groups $(P=0.019)$, with $67 \%, 71 \%$, and $83 \%$ of control, once-, and twice-weekly groups, respectively, having scores of 3-4. There was no difference in the unadjusted rate of labor induction between the groups (35\% versus $27 \%$ versus $23 \%$, $P=0.149$ ), and after the adjustment for the randomization of Bishop's score (adjusted odds ratio $[\mathrm{OR}]=0.73,95 \%$ confidence interval $[\mathrm{CI}] 0.41-1.29$ and $\mathrm{OR}=0.65,95 \% \mathrm{CI} 0.36-1.18$ for once- and twice-weekly groups, respectively). A Bishop's score of 3-4 at randomization was the only statistically significant factor that decreased the likelihood of induction at 41 weeks (OR $=0.42,95 \%$ CI 0.25-0.69).

Conclusion: Frequency of membrane sweeping does not influence the likelihood of remaining undelivered at 41 weeks of pregnancy. The Bishop's score at around 39 weeks is the important factor as a predictor of the duration of pregnancy, and further studies would be required to determine whether membrane sweeping influences pregnancy duration.

Keywords: labor induction, postmaturity pregnancy, Bishop's score, pregnancy duration

\section{Introduction}

Pregnancies that extend beyond 42 weeks of gestation are at an increased risk for fetal postmaturity syndrome, macrosomia, fetal intolerance of labor, oligohydramnios, meconium-stained amniotic fluid, and cesarean delivery. ${ }^{1-3}$ The clinical evidence of an increased potential for these poor perinatal outcomes has triggered a movement toward increased antenatal testing between 41 and 42 weeks of gestation, and cervical ripening with labor inductions at or before 42 weeks of gestation. ${ }^{4}$ An induction of labor in women with an unfavorable cervix can result in a failed induction in over $50 \%$ of all cases. ${ }^{5}$

The natural course of an unfavorable cervix at term is highlighted by two published investigations. In one investigation, $60 \%$ of women with an unfavorable cervix at 41 weeks of gestation remained undelivered 1 week later when no intervention
Correspondence: Everett F Magann Department of Obstetrics and Gynecology, University of Arkansas for the Medical Sciences, 430I West Markham St \#518, Little Rock, AR 72205-7199, USA

Tel +I 50 I 6868345

$\mathrm{Fax}+$ I 5015267820

Email efmagann@uams.edu 
was undertaken. ${ }^{6}$ In the other study, $56 \%$ of women with an unfavorable cervix at 39 weeks of gestation remained undelivered 3 weeks later in the absence of any interventions. ${ }^{7}$ One of the techniques used to ripen an unripe cervix and to prevent a postterm labor induction is membrane sweeping. A number of investigations have looked at the benefits of cervical ripening by serial membrane sweeping in women with an unfavorable cervix. Compared with expectant management, serial membrane sweeping resulted in a reduction in the number of women who remained undelivered in the two studies cited above with a reduction to $17 \%$ in one of the studies ${ }^{6}$ and $0 \%{ }^{7}$ in the other. With no statistical increase in morbidity, ${ }^{8,9}$ Cochrane Reviews of membrane sweeping to induce labor and to prevent postterm pregnancies found that sweeping was associated with a reduction in pregnancy duration, a reduction in the frequency of pregnancies continuing beyond 41 weeks, and a reduction in the necessity of more formal methods of labor induction. These reviews reported that the use of membrane sweeping showed no differences in the risk for maternal or neonatal infections between control and membrane-swept groups.

Despite the wide use of membrane sweeping, the optimal frequency to prevent postmaturity pregnancies has not been established. The authors' hypothesis for this study was that increased frequency of membrane sweeping is more effective in preventing pregnancies remaining undelivered at 41 weeks. The purpose of this investigation, therefore, was to determine if the frequency of membrane sweeping, twice weekly versus once weekly, in women with an unfavorable cervix at 39 weeks of pregnancy would be more effective in preventing pregnancies remaining undelivered at 41 weeks and being admitted for labor induction.

\section{Materials and methods}

This study was a randomized trial of women with an unfavorable cervix at 39 weeks \pm 2 days and who were planning on, and had no contraindication to, a vaginal delivery. This study could not be blinded to the membrane sweeping investigator but was blinded to all other providers and to the investigator collecting data on each participant. This study was approved by the Chief of Navy Bureau of Medicine and Surgery, Washington, DC, through the local Clinical Investigation Program (International Review Board) (P04-079).

Women at 39 weeks \pm 2 days gestation with an unfavorable cervix, a singleton pregnancy, $\geq 18$ years of age, reliable pregnancy dating that included a first trimester ultrasound, ultrasound confirming that the placenta was clear of the cervix, and who had no contraindication to a vaginal delivery were eligible to participate. These women had to be enrolled at the Naval Medical Center - Portsmouth obstetrics/gynecology clinic with plans to be delivered at this hospital. All women who met eligibility criteria and desired to participate were examined at 39 weeks \pm 2 days and had a Bishop's score assigned. If the Bishop's score was $<4$ and the patient had no contraindication to a vaginal delivery, the patient was invited to participate in the investigation. All Bishop's score assessments were done by three of the providers (KP, EM, and $\mathrm{WW}$ ) with $80 \%$ of the initial and follow-up exams done by one provider (KP). At the 39-week visit, assessment of the cervix to determine the Bishop's score randomization and the first intervention (control, once-weekly sweep, or twice-weekly sweep) was done.

The method of randomization and group assignment was determined by drawing a card from a sealed opaque envelope that would assign the participants to Group I (control), Group II (once-weekly sweeping), or Group III (twice-weekly sweeping). The cards were prepared in blocks of 30 envelopes. Group I, the control group, had their cervix examined weekly but did not have their membranes swept; Group II had weekly membrane sweeping, and Group III had twice-weekly membrane sweeping.

The technique of membrane sweeping was defined as separating the fetal membranes from the lower uterine segment with two circumferential sweeps by the examining finger. If the cervix did not permit entrance of the finger on examination, the finger was placed into the cervix and two circumferential sweeps were done. This was done serially depending on the frequency of the group assignment until entrance of the examining finger could be accomplished. Women in the control group had their cervix examined and the Bishops' score recorded every 7 days. Group I women had their membranes swept every 7 days and Group II women had their membranes swept every 3-4 days. Membrane sweeping was continued according to the assigned frequency until 41 weeks of gestation. At 41 weeks, all remaining women were admitted to the hospital for labor induction.

A sample size was calculated prior to the start of the study. It was calculated that a total of 345 women (115 from each study arm) would be needed to detect a difference between treatment arms and the rates of pregnancies that would remain undelivered at 41 weeks. Assuming that $50 \%$ of pregnancies would remain undelivered at 41 weeks without membrane sweeping, a sample of 345 women was sufficient to detect $40 \%$ and $30 \%$ of pregnancies remaining undelivered with membrane sweeping performed once and twice weekly, respectively, with $80 \%$ power while using chi-square test at $5 \%$ 
significance level (two degrees of freedom with an effect size of 0.167) (PASS 2000 software; NCSS, Kaysville, UT).

Statistical analysis was conducted on an intention-totreat basis. Medians and interquartile ranges were used to summarize continuous data. Frequency distributions were used to summarize categorical data. Univariate comparisons between the three membrane-sweeping groups were conducted using Kruskal-Wallis nonparametric analysis of variance for continuous data and chi-square tests or Fisher exact tests for categorical data, as appropriate. Multivariable analyses of the effects of membrane sweeping on binary outcomes, such as remaining undelivered at 41 weeks and cesarean delivery, were performed using logistic regression analysis while adjusting for important prognostic factors. Comparisons of duration of time from admission to delivery, and time between randomization and delivery were conducted using the Kaplan-Meier log-rank test. Cox proportional hazards regression analysis was used to examine simultaneous factors affecting duration between randomization and admission (inductions of labor were censored) and between admission and delivery (cesarean deliveries were censored). In regression analyses, odds ratios (OR) and hazard ratios (HR) together with their 95\% confidence intervals (CIs) were used to summarize the covariate effects. Candidate prognostic factors included: nulliparity, initial and admission Bishop's score, obstetric characteristics including gestational age at recruitment and at admission, as appropriate for the analysis of each outcome considered. All hypothesis tests were two-sided and $P$ values $<0.05$ were considered statistically significant.
Statistical analysis was performed using SPSS statistical software (v 16; IBM Corp, Armonk, NY).

\section{Results}

Between January 2005 and June 2008, there were 389 eligible women, of whom 355 were randomized (Figure 1). Five women withdrew from the study, one in the control group and two each in the once-weekly and twice-weekly sweeping groups. One patient in the twice-weekly group withdrew because of the discomfort of the membrane sweeping and the others withdrew because of a desire to be induced prior to 41 weeks; although, the authors' policy is not to induce for a postmaturity pregnancy until 41 weeks. Median gestational age at recruitment was 39 weeks and median duration of monitoring until delivery was 9 days (interquartile range 6-14, range 0-19 days). Baseline characteristics of the groups were similar (Table 1), with the exception of Bishop's scores at recruitment $(P=0.019)$. Significantly higher proportion of women randomized into the twice-weekly membrane-sweeping group had initial Bishop's scores of 3-4 compared with women randomized to once-weekly membrane sweeping ( $P=0.040,82.9 \%$ versus $70.9 \%$ ) and compared with women randomized into the control group $(P<0.001,82.9 \%$ versus $67.2 \%)$. The women randomized into one of the active membrane-sweeping study arms underwent the procedure at least once. After initial sweeping at 39 weeks in the active sweeping groups, 22 women $(18.8 \%)$ in the once-weekly group underwent one additional membrane-sweeping procedure (this included

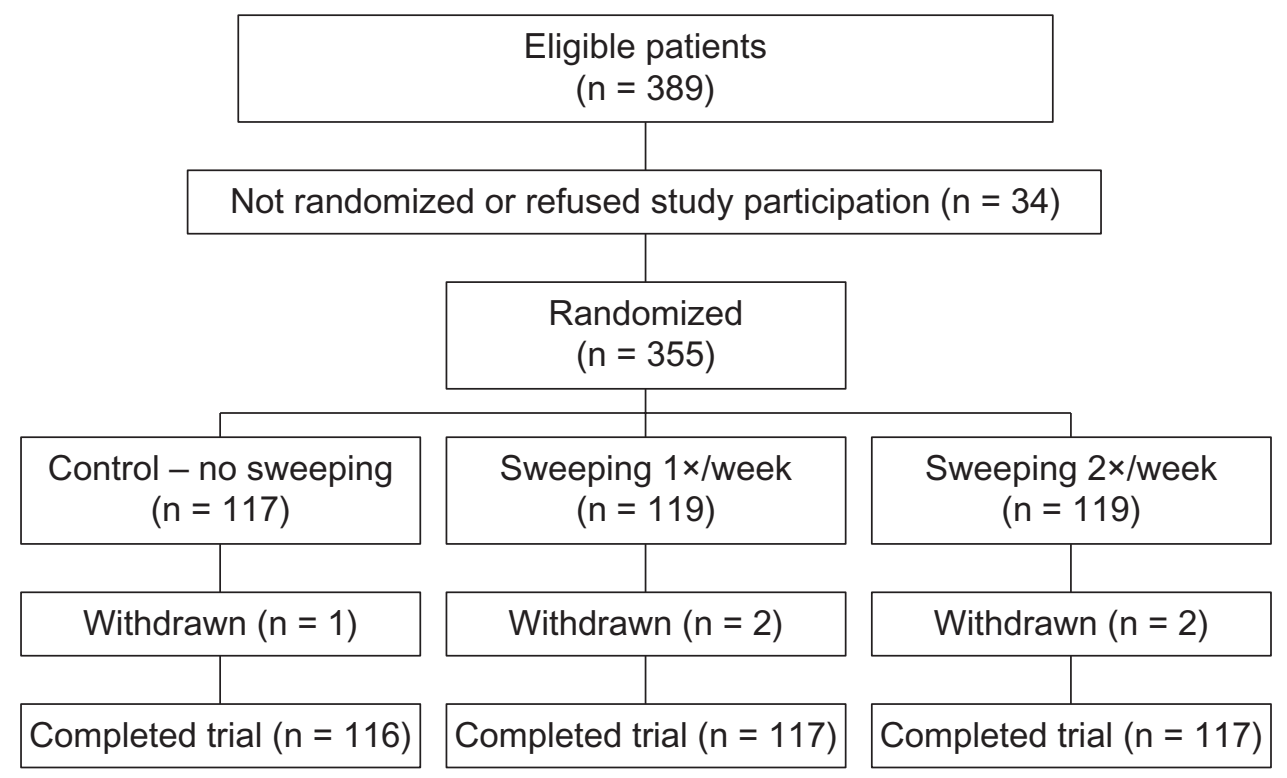

Figure I Flow diagram of the randomized controlled trial of membrane sweeping frequency. Abbreviation: $n$, number. 
Table I Population demographics at baseline. Unless otherwise stated $\mathrm{n}(\%)$ are shown

\begin{tabular}{|c|c|c|c|c|}
\hline & $\begin{array}{l}\text { No sweep } \\
(n=116)\end{array}$ & $\begin{array}{l}\text { Once-weekly sweep } \\
(n=|| 7)\end{array}$ & $\begin{array}{l}\text { Twice-weekly sweeps } \\
(\mathrm{n}=1 \mid 7)\end{array}$ & $P$ value \\
\hline \multirow[t]{2}{*}{ Maternal age $^{\dagger}$} & $24(2 I-28)$ & $24(21-29)$ & $24(2 I-28)$ & 0.607 \\
\hline & [19-42] & {$[18-40]$} & {$[18-47]$} & \\
\hline$<20$ & $8(6.9)$ & $9(7.7)$ & $10(8.5)$ & 0.731 \\
\hline $20-34$ & I0I (87.I) & $98(83.8)$ & $102(87.2)$ & \\
\hline $35+$ & $7(6.0)$ & $10(8.5)$ & $5(4.3)$ & \\
\hline \multicolumn{5}{|l|}{ Maternal race } \\
\hline Caucasian & $70(60.3)$ & $78(66.7)$ & 83 (70.9) & 0.243 \\
\hline A-A & $33(28.4)$ & $33(28.2)$ & $24(20.5)$ & \\
\hline Other** & $13(11.2)$ & $6(5.1)$ & $10(8.5)$ & \\
\hline Gravidity ${ }^{\dagger}$ & $2(I-3)[I-6]$ & $2(I-3)[I-8]$ & $2(\mathrm{I}-3)[\mathrm{I}-8]$ & 0.890 \\
\hline Parity ${ }^{\dagger}$ & $0(0-1)[0-4]$ & $0(0-1)[0-4]$ & $0(0-1)[0-4]$ & 0.928 \\
\hline Nulliparous & $74(63.8)$ & $70(59.8)$ & $73(62.4)$ & 0.806 \\
\hline \multicolumn{5}{|c|}{ Bishop's score at recruitment } \\
\hline $0-2$ & $38(32.8)$ & $33(28.2)$ & $20(17.1)$ & 0.019 \\
\hline $3-4$ & $78(67.2)$ & $83(70.9)$ & $97(82.9)$ & \\
\hline \multirow[t]{2}{*}{ GA at recruitment ${ }^{\dagger}$} & $39(38.9-39.2)$ & $39(38.9-39.2)$ & $39(38.9-39.2)$ & 0.458 \\
\hline & [38.7-39.3] & [38.7-39.3] & [38.7-39.3] & \\
\hline
\end{tabular}

Notes: †Median, interquartile range (first-third quartile), and range [minimum-maximum] are shown; ** 0 Asian, 18 Hispanic, I American Indian.

Abbreviations: A-A, African-American; GA, gestational age; n, number.

two women who underwent an additional two procedures). Fifty-three women (45.3\%) were randomized into the twiceweekly group, who underwent membrane sweeping more than once after the initial sweeping at 39 weeks, including 20 women $(20.5 \%)$ who had two additional procedures, 25 women $(21.4 \%)$ who had three additional procedures, three women $(2.6 \%)$ who had four additional procedures, and one woman $(0.9 \%)$ who underwent five additional sweeping procedures prior to delivery.

Significantly, earlier gestational age at admission was observed in the active study groups $(P=0.009$; Table 2$)$. Significantly shorter duration between recruitment and admission $(P=0.018)$ was observed, along with significantly higher Bishop's scores at admission in the active membranesweeping groups $(P<0.001)$. A similar proportion of women remained undelivered and admitted for labor at 41 pregnancy weeks in all three groups $(P=0.149 ; 34.5 \%$ versus $27.4 \%$ versus $23.1 \%$ in control, once-, and twice-weekly groups, respectively). Relative to the control group, the univariate and Bishop's score adjusted OR for the once-weekly group were OR $=0.72,95 \%$ CI $0.41-1.25$, adjusted $\mathrm{OR}=0.73$, $95 \%$ CI $0.41-1.29$, and for twice weekly were $\mathrm{OR}=0.57$, 95\% CI 0.32-1.01, adjusted OR $=0.65,95 \%$ CI 0.36-1.18. Logistic regression analysis factors affecting the likelihood of induction at 41 weeks of pregnancy showed that Bishop's score 3-4 at randomization was the only statistically significant factor that decreased the likelihood of induction at 41 weeks $(\mathrm{OR}=0.42,95 \%$ CI $0.25-0.69, P=0.001)$.
Rates of spontaneous rupture of membranes at admission of $19.8 \%, 17.9 \%$, and $23.1 \%$ for the control, once-, and twice-weekly membrane-sweeping groups, respectively, were similar between groups $(P=0.614$; Table 2$)$. Logistic regression analysis, adjusted for the randomization group, has also identified nulliparity as a characteristic that significantly increases the likelihood of spontaneous rupture of membranes $(\mathrm{OR}=1.94,95 \%$ CI 1.08-3.47, $P=0.026)$. No other factors were evident, except for group B Streptococcus (GBS) on vaginal swab approaching statistical significance $(\mathrm{OR}=1.77$, 95\% CI 0.97-3.22, $P=0.062$ ).

Log-rank comparison of pregnancy duration between the time of randomization and time of admission (with inductions at 41 weeks censored) stratified by the initial Bishop's score indicated no significant differences between the three groups $(P=0.070$; Figure 2$)$. Analysis of pregnancy duration between the time of randomization and time of admission indicated that once-weekly membrane sweeping was similar in pregnancy duration to the control group $(\mathrm{HR}=1.22$, 95\% CI 0.89-1.67, $P=0.223$ ). The twice-weekly membrane sweeping was associated with a shorter duration until hospital admission than the control group $(\mathrm{HR}=1.44,95 \% \mathrm{CI}$ 1.06-1.97, $P=0.020$ ), and this difference was no longer significant after the adjustment for the initial Bishop's score (adjusted HR $=1.29,95 \%$ CI 0.99-1.68, $P=0.055$ ). Relative to a Bishop's score $0-2$ at randomization, a score of 3-4 was indicative of a significantly shorter pregnancy duration until admission $(\mathrm{HR}=1.67,95 \%$ CI $1.23-2.28, P=0.001)$. 
Table 2 Obstetric outcomes for three randomization groups. Unless otherwise stated $\mathrm{n}(\%)$ are shown

\begin{tabular}{|c|c|c|c|c|}
\hline & $\begin{array}{l}\text { No sweep } \\
(n=116)\end{array}$ & $\begin{array}{l}\text { Once-weekly sweep } \\
(\mathrm{n}=1 \mathrm{II})\end{array}$ & $\begin{array}{l}\text { Twice-weekly sweeps } \\
(\mathrm{n}=1 \mathrm{I} 7 \mathrm{7})\end{array}$ & $P$ value \\
\hline \multirow[t]{2}{*}{ GA on admission ${ }^{\dagger}$} & $40.6(39.9-41.0)$ & $40.4(39.9-41.0)$ & $40.2(40.7-39.7)$ & 0.009 \\
\hline & {$[38.7-4 \mid .7]$} & {$[38.7-41.7]$} & {$[39.0-41.7]$} & \\
\hline Recruitment-admission & II (6-14) [0-19] & $10(6-14)[0-18]$ & $8(5-12)[0-19]$ & 0.018 \\
\hline \multicolumn{5}{|l|}{ interval (days) ${ }^{\dagger}$} \\
\hline Bishop's score on admission ${ }^{\dagger}$ & $7(4-10)[1-13]$ & $7(6-14)[I-12]$ & $8(5-12)[1-13]$ & 0.010 \\
\hline \multicolumn{5}{|l|}{ Bishop's score } \\
\hline $0-4$ & $33(28.4)$ & $13(11.1)$ & $10(8.5)$ & $<0.001$ \\
\hline $5-9$ & $54(46.6)$ & $77(65.8)$ & $77(65.8)$ & \\
\hline $10-13$ & $29(25.0)$ & $27(23.1)$ & $30(25.6)$ & \\
\hline Remaining undelivered at & $40(34.5)$ & $32(27.4)$ & $27(23.1)$ & 0.149 \\
\hline \multicolumn{5}{|l|}{$\begin{array}{l}41 \text { weeks and admitted for } \\
\text { labor induction }\end{array}$} \\
\hline Admission to delivery & $12.2(7.3-20.0)$ & II.5 (6.I-16.8) & $11.0(6.4-18.3)$ & 0.114 \\
\hline \multicolumn{5}{|l|}{ interval (hours) $)^{\ddagger}$} \\
\hline \multicolumn{5}{|l|}{ Mode of delivery } \\
\hline Vaginal delivery** & $83(71.6)$ & $89(76.1)$ & $87(74.4)$ & 0.730 \\
\hline Cesarean delivery & $33(28.4)$ & $28(23.9)$ & $30(25.6)$ & \\
\hline \multicolumn{5}{|l|}{ Reasons for cesarean delivery } \\
\hline Fetal labor intolerance & $9(27.3)$ & II (39.3) & I3 (43.3) & 0.520 \\
\hline CPD/FTP & $20(60.6)$ & $17(60.7)$ & $15(50.0)$ & \\
\hline Failed induction & $3(9.1)$ & - & $\mathrm{I}(3.3)$ & \\
\hline Malpresentation & I (3.0) & - & I (3.3) & \\
\hline Chorioamnionitis at delivery & $12(10.3)$ & $7(6.0)$ & $9(7.7)$ & 0.466 \\
\hline GBS on vaginal swab & $21(18.1)$ & $25(21.4)$ & $30(25.6)$ & 0.375 \\
\hline \multicolumn{5}{|l|}{ Birth weight $^{\dagger}$ (gm) } \\
\hline \multirow[t]{3}{*}{$<2,500$} & 3,507 & 3,578 & 3,530 & 0.903 \\
\hline & $(3,304-3,818)$ & $(3,225-3,913)$ & $(3,263-3,825)$ & \\
\hline & {$[1,845-4,750]$} & {$[2,245-4,670]$} & {$[2,6|5-4,6| 0]$} & \\
\hline \multicolumn{5}{|l|}{ Apgar score $<7$} \\
\hline I minute & $10(8.6)$ & $8(6.8)$ & $8(6.8)$ & 0.836 \\
\hline 5 minutes & - & - & $2(1.7)$ & 0.331 \\
\hline \multirow[t]{2}{*}{ Umbilical artery $\mathrm{pH}^{\dagger}$} & $7.28(7.23-7.30)$ & $7.29(7.26-7.32)$ & $7.29(7.26-7.31)$ & 0.027 \\
\hline & {$[7.06-7.41]$} & {$[7.05-7.45]$} & {$[7.09-7.43]$} & \\
\hline$<7.21$ & $17(14.7)$ & $14(12.0)$ & $14(12.0)$ & 0.779 \\
\hline$<7.10$ & I (0.9) & $2(1.7)$ & I (0.9) & 0.999 \\
\hline NICU admission & $4(3.4)$ & $2(1.7)$ & $2(1.7)$ & 0.609 \\
\hline
\end{tabular}

Notes: †Median, interquartile range (first-third quartile), and range [minimum-maximum] are shown; *interval between admission and delivery was estimated using KaplanMeier survival probabilities and with all cesarean deliveries censored; **vaginal deliveries include nine assisted vaginal deliveries, $\mathrm{n}=5, \mathrm{n}=3$, and $\mathrm{n}=\mathrm{I}$ for control, one sweep per week, and two sweeps per week, respectively.

Abbreviations: GA, gestational age; GBS, group B Streptococcus; CPD, cephalopelvic disproportion; FTP, failure to progress; NICU, neonatal intensive care unit; n, number.

Group comparison of duration from hospital admission to delivery (with cesarean deliveries censored) showed no effects of membrane sweeping to the time of delivery (relative to the control group, $\mathrm{HR}=1.01,95 \% \mathrm{CI} 0.75-1.38, P=0.931$ and $\mathrm{HR}=1.00,95 \% \mathrm{CI} 0.74-1.40, P=0.985)$ for once- and twiceweekly membrane sweeping, respectively. Simultaneously, higher Bishop's scores at admission were significantly related to the duration until delivery with $\mathrm{HR}=3.25,95 \%$ CI 2.04-5.18 and HR $=7.10,95 \%$ CI $4.28-11.77$ for scores 5-9 and 10-13, respectively. Factors predictive of longer duration included nulliparity $(\mathrm{HR}=0.46,95 \%$ CI $0.36-0.60$,
$P<0.001)$ and later gestational age at the time of admission $(\mathrm{HR}=0.65,95 \%$ CI $0.54-0.80, P<0.001)$.

Rates of fetal intolerance of labor were similar between the groups ( $P=0.894 ; 0.3 \%$ versus $10.3 \%$ versus $12.0 \%$ in the control, once-, and twice-weekly groups, respectively) as well as the rates of cesarean delivery due to fetal intolerance of labor between groups $(P=0.384)$. Chorioamnionitis and GBS on vaginal swabs at admission were similar among groups (Table 2).

Neonatal outcomes including birth weight, Apgar scores at 5 minutes, and admissions to neonatal intensive care unit 


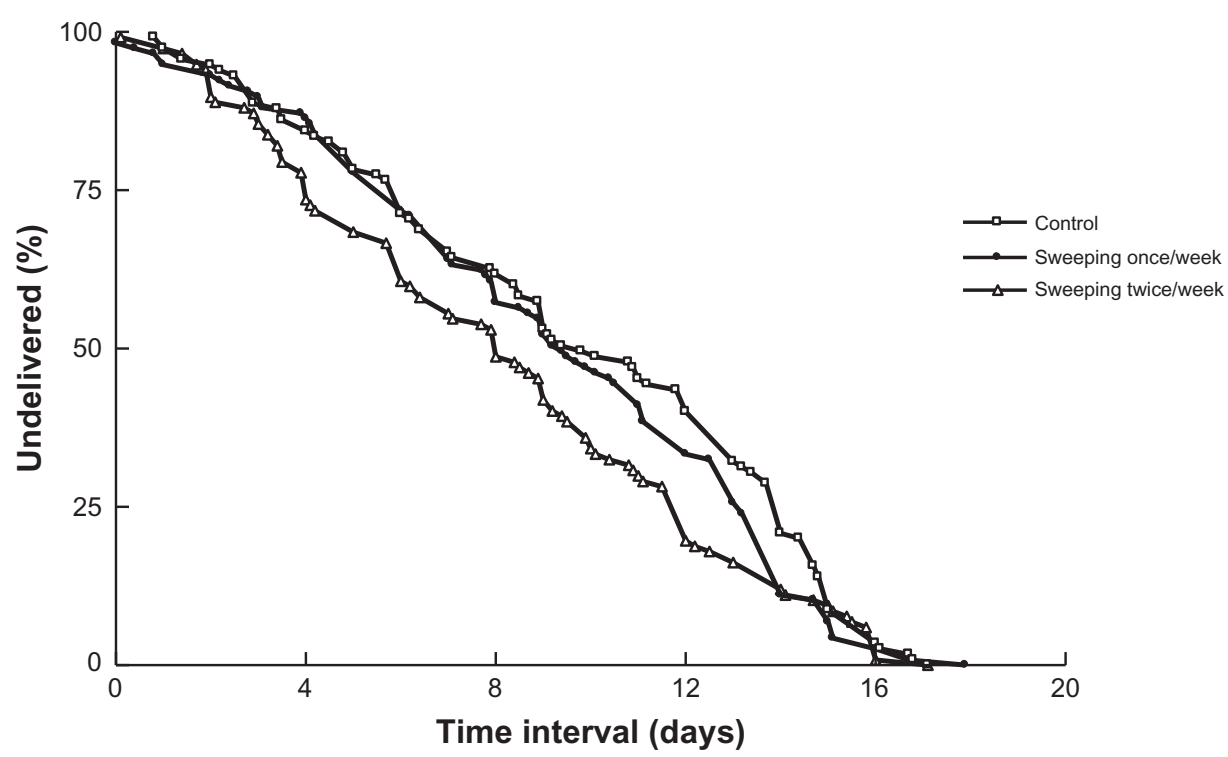

Figure 2 Kaplan-Meier survival curves comparing the time interval between randomization and delivery. Overall and pair-wise log-rank tests were performed to assess the equality of survivor functions.

Note: The results of the survival curve indicate that there were no significant differences between the three groups $(P=0.08 \mathrm{I})$.

were similar between groups (Table 2). Raw $\mathrm{pH}$ measurements were significantly different among groups $(P=0.027)$ due to the lower first-quartile $\mathrm{pH}$ in the control group. This was not translated to any significant differences among groups with respect to $\mathrm{pH}<7.21$ or $\mathrm{pH}<7.1$ ( $P=0.779$ and $P=0.999$, respectively; Table 2).

\section{Discussion}

In this study, a significantly earlier gestational age for hospital admission in the active study groups (once- and twice-weekly membrane sweeping) was observed compared with the control group. The time from hospital admission to time of delivery was not different across all three groups. However, there was a shorter duration of time from recruitment to hospital admission and a significantly higher Bishop's score upon admission in the active study groups compared with the control group. Logistic regression analysis of simultaneous factors was undertaken to determine which factors affected the likelihood of induction for those women remaining undelivered at 41 weeks. The only significant factor noted was a higher Bishop's score at randomization that decreased the likelihood of a 41-week induction. The authors' analysis further stratified the initial Bishop's score at the time of randomization rather than just combining groups and listing them as unfavorable with a Bishop's score $\leq 4$.

It was discovered that the Bishop's scores at randomization were different between the groups with a higher proportion of Bishop's scores 3-4 in the twice-weekly group compared with the once-weekly and control groups. The difference in the initial Bishop's score between the groups was the primary limitation of this study. The randomization process was concealed as appropriate for this investigation. The lack of balance between the study arms reflects the lack of stratification by the initial Bishop's score, the major prognostic factor for duration until labor. In hindsight, the randomization by Bishop's score 0-2 and 3-4 should have been stratified. Previous randomized studies also did not stratify by Bishop's score but presented Bishop's score at baseline, and it appears that in the present study the lack of balance occurred. Subsequently the initial Bishop's score was adjusted for in multivariable analysis and the effects of membrane sweeping could therefore be evaluated while accounting for the initial difference between the Bishop's scores. Often, it is expected that randomization will balance the factors without stratification. It cannot be reliably concluded that membrane frequency decreases the risk of labor inductions at 41 weeks and that the women upon hospital admission would have a higher Bishop's score. The difference could be due to the greater number of women with a 3-4 on their initial Bishop's score at randomization rather than an effect of the frequency of the membrane sweeping on the rate of 41-week labor inductions. (The authors' primary endpoint was "remaining undelivered at 41 weeks"/requiring induction at 41 weeks - and the main endpoint is not different between the groups univariately and after adjustment for initial Bishop's score). The comparison of duration between the randomization and admission indicated a significantly shorter time for the twice-weekly group that was no longer 
statistically significant after the adjustment for the initial Bishop's score. These results may suggest that membrane sweeping may hasten the onset of labor but not decrease the likelihood of postmaturity pregnancies. However, due to the imbalance between the initial Bishop's scores, interpretation of this finding needs to be done with caution.

A second limitation is that women who had a Bishop's score that was so unfavorable that it would not permit entrance of the examining finger into the cervix were not specifically identified and tracked. Identification and tracking of these women would provide very valuable information.

The participants in this study were highly motivated and punctual in keeping their appointments. Military wives were prompted to participate in this study hoping that their delivery would be closer to their due date. Because a large number of their supporting families live outside the military wives' area of residence, travel to be with their daughter or sister around the time of delivery is more prevalent. The closer the delivery is to the due date, the more time these extended families potentially have following that delivery to help the new mother with her newborn. Active duty women and dependent wives who participated in this study missed few appointments. Other than the 34 participants who were either not randomized or refused participation, only five women withdrew during the study.

The findings of this study are different from those already published in the authors' other publications ${ }^{5-7}$ and from the meta-analysis from the Cochrane review, ${ }^{8,9}$ where membrane sweeping is correlated with a reduction in postterm pregnancies. This could be because membrane sweeping usually involves several circumferential sweeps in which the fetal membranes are separated from the lower uterine segment. If the Bishops' score is 1 or 2 , the cervix may not be sufficiently dilated for the examining finger to separate the fetal membranes from the lower uterine segment. Regarding the rates of postterm pregnancies, an examination of the authors' investigations and the Cochrane review reveals that the impact of an exam when the membranes cannot be separated from the lower uterine segment cannot be known. Some studies exclude women when the membranes cannot be reached; ${ }^{10-13}$ others perform a "cervical massage," ${ }^{14-20}$ and in still others, the examining finger is inserted as far into the cervix as possible on serial exams until the membranes can be separated. ${ }^{5-7,21-25}$ The term "cervical massage" is otherwise undefined in these references and this method of ripening the unfavorable cervix in pregnancies in which the membranes cannot be swept is uncertain. Differences in study results could be related to the number of women included in the investigations whose cervix does not permit the examining finger to separate the fetal membranes from the lower uterine segment. In studies with few women in which the membranes cannot be swept, sweeping may show a difference and in those with a larger number of women in which the cervix will not admit the examining finger, there may be no differences observed.

The findings from this study open several new avenues for investigation. The effects of cervical massage and other methods of cervical ripening (insertion of the examining finger serially into the cervix until the membranes can be swept) must be evaluated and related to the exams in which the membranes can be separated from the lower uterine segment on initial examination. Information from these types of comparisons will assist investigators in determining the role of each of these techniques in hastening the onset of labor.

\section{Disclosure}

The authors report no conflicts of interest in this work. The views expressed in this article are the views of the authors and do not necessarily reflect the official policy or position of the US Department of the Navy, US Department of Defense, or the US Government.

\section{References}

1. Ingemarsson I, Kallen K. Stillbirths and rate of neonatal deaths in 76,761 postterm pregnancies in Sweden,1982-1991: a register study. Acta Obstet Gynecol Scand. 1997;76(7):658-662.

2. Clausson B, Cnattingius S, Axelsson O. Outcomes of post-term births: the role of fetal growth restriction and malformations. Obstet Gynecol. 1999;94(5 Pt 1):758-762.

3. Divon MY, Haglund B, Nisell H, Otterblad PO, Westgren M. Fetal and neonatal mortality in the postterm pregnancy: the impact of gestational age and fetal growth restriction. Am J Obstet Gynecol. 1998;178(4):726-731.

4. American College of Obstetricians and Gynecologists Committee on Practice Bulletins-Obstetrics. ACOG Practice Bulletin. Clinical management guidelines for obstetricians-gynecologists. Number 55, September 2004 (replaces practice pattern number 6, October 1997). Management of postterm pregnancy. Obstet Gynecol. 2004;104(3):639-646.

5. Magann EF, Perry KG Jr, Dockery JR Jr, Bass JD, Chauhan SP, Morrison JC. Cervical ripening before medical induction of labor: a comparison of prostaglandin E-2, estradiol, and oxytocin. Am J Obstet Gynecol. 1995;172(6):1702-1706.

6. Magann EF, Chauhan SP, Nevils BG, McNamara MF, Kinsella MJ, Morrison JC. Management of pregnancies beyond forty-one weeks' gestation with an unfavorable cervix. Am J Obstet Gynecol. 1998;178(6): 1279-1287.

7. Magann EF, McNamara MF, Whitworth NS, Chauhan SP, Thorpe RA, Morrison JC. Can we decrease postdatism in women with an unfavorable cervix and a negative fetal fibronectin test result at term by serial membrane sweeping? Am J Obstet Gynecol. 1998;179(4):890-894.

8. Boulvain M, Stan C, Irion O. Membrane sweeping for induction of labour [review]. Cochrane Database Syst Rev. 2001;2:CD000451.

9. Boulvain M, Irion O. Stripping/sweeping the membranes for inducing labor or preventing post-term pregnancy [review]. Cochrane Database Syst Rev. 2000;2:CD000451. 
10. Allott HA, Palmer CR. Sweeping the membranes: a valid procedure in stimulating the onset of labour? Br J Obstet Gynaecol. 1993;100(10): 898-903.

11. Berghella V, Rogers RA, Lescale K. Stripping of membranes as a safe method to reduce prolonged pregnancies. Obstet Gynecol. 1996;87(6): 927-931.

12. Dare FO, Oboro VO. The role of membrane stripping in prevention of post-term pregnancy: a randomised clinical trial in Ile-Ife, Nigeria. J Obstet Gynaecol. 2002;22(3):283-286.

13. Gupta R, Vasishta K, Sawhney H, Ray P. Safety and efficacy of stripping of membranes at term. Int J Gynaecol Obstet. 1998;60(2):115-121.

14. Alcoseba-Lim W, Famador-Juario H. Stripping of the membranes to induce labor at term. Philipp J Surg Surg Spec. 1992;47:139-142.

15. Boulvain M, Fraser WD, Marcoux S, et al. Does sweeping of the membranes reduce the need for formal induction of labour? A randomised controlled trial. Br J Obstet Gynaecol. 1998;105(1):34-40.

16. el-Torkey M, Grant JM. Sweeping of the membranes is an effective method of induction of labour in prolonged pregnancy: a report of a randomised trial. Br J Obstet Gynaecol. 1992;99(6):455-458.

17. Doany W, McCarty J. Outpatient management of postdate pregnancy with intravaginal prostaglandin E2 and membrane stripping. J Matern Fetal Med. 1997;6(2):71-78.

18. Crane J, Bennet K, Young D, Windrim R, Kravitz H. The effectiveness of sweeping membranes at term: a randomized trial. Obstet Gynecol. 1997;89(4):586-590.
19. Wiriyasirivaj B, Vutyavanich T, Ruangsri RA. Randomized controlled trial of membrane stripping at term to promote labor. Obstet Gynecol. 1996;87(5 Pt 1):767-770.

20. Wong SF, Hui SK, Choi H, Ho LC. Does sweeping of membranes beyond 40 weeks reduce the need for formal induction of labour? BJOG. 2002;109(6):632-636.

21. Goldenberg M, Dulitzky M, Feldman B, Zolti M, Bider M. Stretching of the cervix and stripping of the membranes at term: a randomized controlled trial. Eur J Obstet Gynecol Reprod Biol. 1996;66(2):129-132.

22. Cammu H, Haitsma V. Sweeping of the membranes at 39 weeks in nulliparous women: a randomised controlled trial. Br J Obstet Gynaecol. 1998;105(1):41-44.

23. McColgin SW, Patrissi GA, Morrison JC. Stripping the fetal membranes at term. Is the procedure safe and efficacious? J Reprod Med. 1990; 35(8):811-814

24. McColgin SW, Hampton HL, McCaul JF, Howard PR, Andrew ME, Morrison JC. Stripping of membranes at term: can it safely reduce the incidence of post-term pregnancies? Obstet Gynecol. 1990;76(4): 678-680.

25. Tannirandorn Y, Jumrustanasan T. A comparative study of membrane stripping and nonstripping for induction of labor in uncomplicated term pregnancy. J Med Assoc Thail. 1999;82(3):229-232.
International Journal of Women's Health

\section{Publish your work in this journal}

The International Journal of Women's Health is an international, peerreviewed open-access journal publishing original research, reports, reviews and commentaries on all aspects of women's healthcare including gynecology, obstetrics, and breast cancer. Subject areas include: Chronic conditions (migraine headaches, arthritis, osteoporosis);

\section{Dovepress}

Endocrine and autoimmune syndromes; Sexual and reproductive health; Psychological and psychosocial conditions. The manuscript management system is completely online and includes a very quick and fair peer-review system. Visit http://www.dovepress.com/ testimonials.php to read real quotes from published authors. 